Relations industrielles

Industrial Relations

\title{
En la Escuela de lo social. Carlos Giner et Dionisio Aranzadi, Instituto de estudios economico-sociales, Universidad de \\ Deusto, 1958. 257 pp.
}

\section{Gérard Dion}

Volume 14, numéro 3, juillet 1959

URI : https://id.erudit.org/iderudit/1022300ar

DOI : https://doi.org/10.7202/1022300ar

Aller au sommaire du numéro

Éditeur(s)

Département des relations industrielles de l’Université Laval

ISSN

0034-379X (imprimé)

1703-8138 (numérique)

Découvrir la revue

Citer ce compte rendu

Dion, G. (1959). Compte rendu de [En la Escuela de lo social. Carlos Giner et Dionisio Aranzadi, Instituto de estudios economico-sociales, Universidad de Deusto, 1958. 257 pp.] Relations industrielles / Industrial Relations, 14(3), 440-440. https://doi.org/10.7202/1022300ar

Tous droits réservés (C Département des relations industrielles de l’Université Laval, 1959
Ce document est protégé par la loi sur le droit d'auteur. L'utilisation des services d'Érudit (y compris la reproduction) est assujettie à sa politique d'utilisation que vous pouvez consulter en ligne.

https://apropos.erudit.org/fr/usagers/politique-dutilisation/ 
le domaine social de 1871 à 1914. La première partie de ce travail est consacrée à une exposition des conditions de l'action sociale au cours de cetie époque. Dans les autres, l'auteur explore les différents champs d'activité: la famille, le travail urbain, le monde rural et maritime et enfin l'action auprès de l'Etat.

On suit le développement de groupements comme l'A.C.J.F., le Sillon, les Semaines sociales, l'Action populaire, les Secrétariats sociaux, le syndicalisme chez les employ'és, les organisations agricoles, etc. Des hommes, des équipes se forment et travaillent au milieu de difficultés fornłidables. Il est même surprenant qu'ils aient réussi à tenir le coup et à jeter les bases d'institutions qui ne pourront porter vraiment des fruits qu'après la première Grande guerre.

Cette époque a connu la crise du Modernisme, la Loi de Séparation, le Sillon, l'Accion française, etc. Les esprits conservateurs qui s'opposent à tout progrès avaient beau jeu pour utiliser l'opération classique de divension et camoufler leurs visées sociales et politiques derrière une prétendue orthodoxie qu'ils mettaient honteusement à leur service. Ils étaient d'ailleurs bien organisés. Quand on voit les attaques insidieuses des intégristes et les moyens dont ils disposaient dans les endroits stratégiques pour diffamer l'un après l'autre tous les groupements ou toutes les personnalités qui voulaient faire quelque chose dans le domaine social, on ne peut s'empêcher de songer qu'ils ont été sûrement parmi les plus grands responsables de l'abandon de l'Eglise par les masses populaires. Combien de fois, l'Action populaire, les Semaines sociales, les instigateurs du syndicalisme et d'oeuvres sociales ont perdu un temne précieux devant les Congrégations romaines pour s'expliquer, pour rectifier de faux rapports, pour se défendre. Il a fallu à tous une foi, un courage, une énergie indomptables pour réussir à passer à travers ces obstacles et continuer leur oeuvre avec l'approbation et le soutien de certains évêques clairvoyants.

Des ouvrages comme celui-ci rendent de très grands services. Ils nous permettent de constater comment le bien ne se fait pas tout seul. Ceux qui militent aujourd'hui dans le domaine social, comme tous ceux qui ont des responsabilités tireront grand avantage à con- naître cette histoire. Comme toute histoire bien faite, elle est une sagesse qui aide à apprécier le mouvement des idées, les hommes et les institutions dans une perspective plus large et dégagée de certaines contingences essentiellement caduques.

A cause du rôle important que joue la France au sein de l'Eglise et de l'influence qu'exercent les caiholiques sociaux de ce pays sur le Canada français, nous ne pouvons pas ignorer un ouvrage comme celui de M. Rollet. Même si ce n'était que pour nous metre en garde contre les difficultés et les embuches de cette époque - lesquelles, on le sait, ont toujours dhez nous leur effet à retardement - ce serait déjà beaucoup de leçons à apprendre.

\section{GÉrard Dion}

\section{En la Escuela de lo social. Carlos Giner et Dionisio Aranzadi, Instituto de estudios economico-sociales, Universi- dad de Deusto, 1958. 257 pp.}

Cet ouvrage n'a pas de prétention scientifique. C'est un manuel destiné à la formation sociale de la jeunesse. Les auteurs utilisent la méthode préconisée par la JOC: voir, juger, agir. Chaque chapitre est précédé d'un questionnaire bien fait. Ensuite, on procède de la manière suivante: un fait de la vie courante ou un exposé de doctrine est présenté au lecteur et ce n'est qu'après cela que l'on explique ce qu'en pense l'Eglise. Les auteurs connaissent bien tous les manuels d'enseignement social de l'Eglise, qui, pour la plupart, d'ailleurs, ont été traduits en espagnol. Ils sonit bien documentés, mais leur travail, qui est bien clair, bien divisé reste trop théorique, trop livresque Nous ne croyons pas qu'il fasse avancer la science, mais il semble proportionné au niveau des personnes auxquelles il est destiné et contribuera à créer chez eux une inquiétude salutaire.

GÉrard Dion

Contemporary Collective Bargaining in Seven Countries, par Adolf Sturmthal et d'autres, The Institute of International Industrial and Labor Relations, 